\title{
O trabalho pedagógico com a cultura corporal afro-brasileira na escola: um estudo bibliográfico
}

\begin{abstract}
Resumo:
Observa-se que as publicações acadêmicas referentes à cultura corporal afro-brasileira têm crescido significativamente desde a década de 1980. Diante disso, a presente pesquisa objetivou identificar como é trabalhada a cultura corporal afro-brasileira na escola, expressa nos relatos de experiências publicados em revistas científicas e anais de congressos específicos da área de Educação Física brasileiros disponíveis online até 2017. Os procedimentos metodológicos utilizados foram de pesquisa bibliográfica e da análise de conteúdo e, para a coleta de dados, utilizou-se o buscador da internet Google Acadêmico. Como resultado, verificou-se um crescimento das práticas pedagógicas que abordam a capoeira, a dança-afro e outras manifestações da cultura corporal nas aulas de Educação Física, porém realizadas na sua maioria por profissionais externos à escola e por outras instituições de ensino.
\end{abstract}

\section{Palavras-chave:}

Cultura afro-brasileira. Educação Física. Escola.

\begin{abstract}
:
It is observed that academic publications referring to Afro-Brazilian corporal culture is significantly growing since 1980 decade. Thus the present study aimed to identify how the Afro-Brazilian corporal culture is being worked at schools expressed in reports of experiences published at Brazilian scientific journals and annals of congresses of Physical Education area, those available online up to 2017. As methodological procedures were utilized bibliographical research and content analysis, in order to collect data the Google Academic was utilized. As result, it was verified a pedagogical practices growth that evolves capoeira, afro dance and other corporal culture manifestations in Physical Education classes. However, the majority is being conducted by professionals external to school as well by other teaching institutions.
\end{abstract}

\section{Keywords:}

Afro-Brazilian culture. Physical Education. School.

\footnotetext{
* Doutor em Educação pela UFRGS, mestre em Ciência do Movimento Humano pela UFSM, professor de Educação Física do Colégio de Aplicação da UFRGS. E-mail: ivan.livindo@ufrgs.br. ORCID iD: http://orcid.org/0000-0003-0186-6511.
} 


\section{Introdução}

Os estudos críticos da Educação Física brasileira apontam que, historicamente, concepções científicas e socioculturais distintas pautam as práticas pedagógicas escolares. Com isso, a Educação Física escolar sofreu, inicialmente (século XIX e XX), forte influência das Ciências Biológicas e das instituições médicas e militares, as quais tinham a intenção de melhorar a saúde da população, bem como preparar os futuros soldados e trabalhadores necessários ao desenvolvimento da economia nacional. (BRACHT, 1992; FERREIRA, 1995; HALLAL; MELO, 2017).

$\mathrm{Na}$ atualidade, essas concepções ainda influenciam muitas práticas pedagógicas voltadas à promoção da saúde e à melhoria da qualidade de vida. Além da primazia pela promoção da saúde, a Educação Física do século XX aproximou-se das instituições esportivas, na iminência de os esportes tornarem-se as práticas pedagógicas predominantes na escola. (BRACHT; GONZÁLEZ, 2014; HALLAL; MELO, 2017).

Nos anos 80 do século XX, surgiu um movimento crítico às práticas predominantes na Educação Física escolar e, consequentemente, construíram-se diversas propostas de mudanças curriculares para a Educação Física, as quais geraram novas concepções pedagógicas ${ }^{1}$, dentre essas, destaca-se a concepção pedagógica intitulada: "crítico-superadora". Essa concepção é fruto da reflexão conjunta de um coletivo de pensadores que, em 1992, publicou o livro: Metodologia do Ensino de Educação Física (SOARES et al., 1992). Nesta obra, a Educação Física é definida como a área de conhecimento que trata da cultura corporal e, pela primeira vez, aborda a cultura afro-brasileira, reconhecendo a capoeira como conteúdo escolar. Segundo Soares et al. (1992, p. 79), “a capoeira encerra em seus movimentos a luta de emancipação do negro no Brasil escravocrata. Em seu conjunto de gestos, a capoeira expressa de forma explícita, a 'voz' do oprimido na sua relação com o opressor”. Desde então, vêm crescendo os ensaios, relatos de pesquisas e de experiências com o ensino de capoeira e de dança afro no espaço escolar.

Pode-se dizer que o movimento crítico da Educação Física estimulou a inserção da cultura corporal afro-brasileira na escola - atualmente, amparada pela Lei no 11.645 (BRASIL, 2008) - e, por conseguinte, fundamentou os relatos de experiências e propostas pedagógicas para o trabalho dessa temática na escola. Essas propostas têm sido publicadas em congressos, seminários, livros e revistas científicas da área de Educação Física. Tomando como exemplo, somente nas teses e dissertações disponíveis no banco de teses ${ }^{2}$, encontram-se 967 trabalhos que estudam a capoeira como manifestação da cultura corporal afro-brasileira. Isso demonstra que as experiências e produções científicas no que se refere à cultura corporal afro-brasileira têm sido objeto de estudo significativo na Educação.

Diante disso, a presente pesquisa objetivou identificar como é trabalhada a cultura corporal afro-brasileira na escola, expressa nos relatos de experiências publicados em revistas científicas e anais de congressos específicos da área de Educação Física brasileiros disponíveis online até 2017.

A pesquisa caracterizou-se por ser uma pesquisa bibliográfica, na qual, de acordo com Minayo (1993, p. 98), deve-se "destacar as categorias centrais, os conceitos e as noções usadas pelos diferentes autores". As publicações científicas selecionadas foram aquelas encontradas em periódicos e anais de eventos específicos da Educação Física.

Para a coleta dos dados, utilizou-se o buscador da internet Google Acadêmico ${ }^{3}$, que possui uma abrangência ampla, por incluir todo o tipo de material acadêmico. Priorizaram-se a análise de resumos,

\footnotetext{
1. Como não é intenção neste estudo analisar as concepções pedagógicas da Educação Física Escolar, não trataremos detalhadamente essa temática, porém, para a compreensão do leitor, esclarecemos que as concepções pedagógicas constituem-se em: fenomenológica; sociológica; cultural; desenvolvimentista; construtivista; concepção de aulas abertas a experiências; voltada para o lazer; crítico-emancipatória; plural; aptidão física/saúde; e, crítico-superadora (FERREIRA, 1995; CORRÊA; MORO, 2004; BRACHT; GONZÁLEZ, 2014). 2. Catálogo de teses e dissertações da CAPES. Disponível em: https://catalogodeteses.capes.gov.br/catalogo-teses/\#!/. Acesso em: 15 jun. 2020.

3. Para Mugnaini e Strehl (2008, p. 99), o Google Acadêmico (GA) caracteriza-se por sua abrangência ampla, porque "reúne as informações disponíveis nas diversas bases de dados de texto completo em uma única interface de busca [...]. Essa facilidade somente é possível devido ao consentimento de muitas das grandes editoras, bases de dados, arquivos de pré-prints, universidades, entre outras organizações, que autorizam o acesso aos conteúdos que publicam, tendo como contrapartida o aumento da visibilidade dos trabalhos".
} 
trabalhos completos disponíveis nos anais do Congresso Brasileiro de Ciências do Esporte desde 1988 até 2017, além de anais de congressos regionais e seminários disponíveis no site do Colégio Brasileiro de Ciências do Esporte ${ }^{4}$. Além dos anais, analisaram-se artigos relacionados às temáticas nas seguintes revistas: Revista Brasileira de Ciências do Esporte, revista Movimento, revista Motrivivência e revista Motriz.

Referente à temática, encontraram-se 170 trabalhos publicados: 96 resumos e trabalhos completos concernentes à capoeira, 17 referentes à dança de raiz africana e 21 que dizem respeito ao corpo negro, quilombolas e cultura corporal afro-brasileira; além de 27 artigos publicados em revista referente à capoeira, 1 referente à dança de raiz africana e 8 referentes ao corpo negro, quilombolas e cultura corporal afro-brasileira.

Após identificar os artigos e resumos que tratam da cultura corporal afro-brasileira no período de 1988 a 2017, selecionou-se 32 que relatam experiência de ensino da cultura corporal de origem afro na escola e 14 trabalhos que expõem pesquisas que dizem respeito às experiências de ensino da cultura corporal afro-brasileira na escola.

Após a identificação dos trabalhos de relatos de experiências, analisaram-se esses documentos através da metodologia de análise de conteúdo (FRANCO, 2008). Primeiro, procedeu-se a uma pré-análise, que consistiu em uma leitura fluente para reconhecer o texto e identificar a temática objetivada na pesquisa.

Após a pré-análise, fez-se a categorização do conteúdo. Segundo Franco (2008, p. 59), "a categorização é uma operação de classificação de elementos constitutivos de um conjunto, por diferenciação seguida de analogias, a partir de critérios definidos". Para o autor, o processo de categorização é demorado e perpassa toda a análise dos dados, sendo que as categorias de análise podem ser elencadas a priori ou a posteriori do contato com o conteúdo a ser analisado.

Para o desenvolvimento desta pesquisa, elaboraram-se as seguintes categorias: como a cultura afro-brasileira é trabalhada na escola; manifestações da cultura corporal afro-brasileira abordadas na escola; procedimentos metodológicos adotados; fundamentação teórica que sustenta o trabalho com a cultura corporal afro-brasileira.

\section{A cultura corporal afro-brasileira}

A compreensão de cultura corporal afro-brasileira como fruto da construção de um determinado povo aproxima-se do conceito de corporeidade como corpo vivido, sentido, criador e criação. Conforme Santin (2003), a corporeidade e os estudos do corpo pela Antropologia abrangem toda a ação humana. "O gesto e a palavra são os amplificadores do universo significativo, isto é, do universo humano. O corpo e seus movimentos estão sempre no centro de toda e qualquer manifestação e possibilidade expressiva" (SANTIN, 2003, p. 68). Como exemplos de expressividade da cultura corporal afro-brasileira têm-se a dança, a capoeira, o samba e o carnaval, que estão repletos de significados corporais dos negros no Brasil.

Pode-se afirmar que as expressões da cultura corporal afro-brasileira são um exemplo da vivência de uma corporeidade plena. Guerra (2008) registra que "o africano canta e dança em diversos eventos da comunidade a que pertence e das mais variadas formas que a criatividade e a espiritualidade lhe concedem, mas, especialmente para celebrar a vida!”. Assim, pergunta-se: como seria possível a manifestação dessa corporeidade dentro da escola, visto que o tempo, os gestos e as atitudes no espaço escolar tendem a serem controlados e pré-determinados?

$\mathrm{Na}$ Educação Física escolar, que tem uma tradição no ensino da ginástica e do esporte, como contemplar a plenitude das manifestações da cultura afro-brasileira? Para Daólio (1995, p. 36), "é possível discutir o corpo como uma construção cultural, já que cada sociedade se expressa diferentemente por meio de corpos diferentes". Eis uma questão para a Educação Física, como tratar, no espaço escola, as diversidades culturais corporalmente vivenciadas por nossos estudantes?

4. Disponível em: http://www.cbce.org.br/anais.php. Acesso em: 15 jun. 2020. 
Cientes das peculiaridades da cultura afro-brasileira, os esforços desta pesquisa é compreender como essa cultura passa a ser abordada nas práticas pedagógicas da Educação Física na escola. De acordo com Guerra (2008, p. 2), a cultura corporal africana manifesta-se na "dança, corpo, movimento, sons, ritmos, palavras, contagiando e penetrando no seu eu e nos outros seres a sua volta, o ímpeto mais sublime de 'energia vital' que no Brasil é chamado de Axé”. As manifestações mais conhecidas da cultura corporal afro-brasileira são a capoeira, o carnaval e os rituais religiosos, sendo que todas envolvem a dança, o canto, o jogo, a música e sempre repletas de espiritualidade (GUERRA, 2008). Neste estudo, compreendem-se como manifestação da cultura afro-brasileira a dança, a capoeira, o samba e o carnaval, divisão somente didática, que contempla a musicalidade, a corporeidade e as expressões rítmicas próprias dessa cultura.

Segundo Corrêa (2012, p. 88), a dança está presente em todas as manifestações culturais, "em todos os registros históricos encontra-se a presença da dança em rituais religiosos, festas populares, nas atividades sociais de salão e em manifestações artísticas ou de espetáculos”. No que se refere à cultura afro-brasileira, a dança encontra-se em todos os espaços de sua manifestação, nos momentos litúrgicos, nas festividades populares, nos salões e nos palcos. Pode-se dizer que a dança afro-brasileira é uma transcendência dos rituais religiosos de culto aos orixás, adaptados aos espaços que ela ocupa. Por exemplo, existem espaços distintos para as danças artísticas e as danças midiatizadas e/ou comercializadas.

As danças artísticas de características afro-brasileiras fazem uso de diferentes recursos e linguagens expressivas próprias para a criação das suas coreografias e, ao criarem, improvisarem e/ou adaptarem movimentos das danças tradicionais populares, têm, como resultado, um espetáculo que se pode identificar como dança-afro ou dança negra. Para Paixão (2009), essa produção tem características multifacetadas, híbridas que se diferenciam dos trabalhos denominados de cultura popular, porque introduzem conhecimentos e técnicas especializadas das artes cênicas e criam outros significados para a cultura popular de viés africana. Essas manifestações artísticas incorporam em sua produção a cultura afro-brasileira.

Referentes às danças midiatizadas, Silveira, Cardoso e Sabbag (2008, p. 4) trazem o exemplo dos dançarinos de axé, os quais expressam "uma visão mais voltada à exposição corporal, de realizar movimentos perfeitos, mostrando seu corpo, também perfeito e sempre voltados à sensualidade, costumam chamar a atenção através da forma de atuar com seu corpo". Ao trazer essa reflexão, propõe-se um debate sobre a corporeidade no espaço escolar. Como um local que historicamente valoriza a racionalidade, a disciplina e a cultura escrita (FREIRE, 1987), faz-se possível vivenciar a cultura corporal afro-brasileira repleta de alegria e de liberdade?

Entende-se que tanto a dança como a capoeira devem ser introduzidas no currículo escolar de múltiplas formas, tanto pelo viés da cultura popular como pelo viés das Artes, dos esportes e dos meios de comunicações de massa. No entanto, a Lei 9394/96 (BRASIL, 1996), modificada por diversas leis, prevê a presença do ensino da cultura afro-brasileira na escola e também inclui o ensino da dança como linguagem artística. Já na Base Nacional Comum Curricular (BRASIL, 2017), a dança aparece como arte e também como um dos conteúdos da Educação Física escolar.

A capoeira é considerada como uma marca da cultura brasileira e um símbolo da luta dos povos africanos no Brasil (SOARES et al., 1992; FALCÃO, 1994), incluindo, em suas práticas, aspectos que lembram uma dança, um jogo ou uma luta. Não existe uma única forma de praticar a capoeira, em seu desenvolvimento histórico, encontram-se referências a movimentos de Capoeira Angola, Capoeira Regional e Capoeira Contemporânea.

A Capoeira Angola, através de seus mestres, professores e praticantes, valoriza os movimentos dos primeiros "capoeiras", sendo o Mestre Pastinha ${ }^{6}$ tido como o precursor. A Capoeira Angola distingue-se pelo arranjo dos instrumentos ${ }^{7}$, toques, cantigas e pela composição da roda. De acordo com Castro Júnior

\footnotetext{
5. O sujeito "capoeira", na linguagem própria da capoeira, é a pessoa que vive essa manifestação cultural. O "capoeira" joga, canta, toca e envolve-se na organização das atividades de capoeira.

6. Mestre Pastinha (1889-1981) organizou, nos anos 1940, em Salvador, uma escola de capoeira onde se ensinavam os fundamentos da capoeira vivenciada na tradição cultura oral dos "capoeiras" da Bahia (CORRÊA, 2012).

7. A organização de uma roda de capoeira está centrada na organização da bateria que é composta por três berimbaus, três caxixis (chocalho), dois pandeiros, um reco-reco, um agogô e um tambor.
} 
(2004, p, 147), “[...] na roda de capoeira, não se canta por cantar: o canto tem sentido e significado. E o cantador canta a partir do jogo". Com isso, a Capoeira Angola aborda, através dos diálogos na roda, os aspectos da musicalidade, da ancestralidade e da espiritualidade. $\mathrm{O}$ "angoleiro", como é denominado o praticante desse movimento, preza o respeito aos antepassados, aos mestres e busca o seu desenvolvimento musical, técnico e espiritual. No entanto, a empregabilidades dos movimentos da Capoeira Angola transcendem aos golpes de uma luta, eles fluem como um diálogo de pergunta e resposta, onde sobressai a malícia em detrimento da força e da velocidade.

A Capoeira Regional, segundo Campos (2009), foi sistematizada pelo Mestre Bimba (1899-1974), que desenvolveu um método, chamado "curso de capoeira regional baiana”. Fruto dos esforços do Mestre Bimba, nos anos 1930, a capoeira foi reconhecida pelo governo federal e liberada a abertura de escolas de capoeira. Entretanto, Mestre Bimba abriu sua escola de Luta Regional Baiana, em que priorizava o ensino para estudantes e trabalhadores. Assumindo-se como uma luta, a Capoeira Regional cria graduações nas quais os participantes vão trocando de "corda" , conforme a evolução no processo aprendizagem. É reconhecido o movimento da Capoeira Regional, o qual tem influenciado a formação de diversos grupos de capoeira e pautado o processo de introdução da capoeira no currículo escolar. Pode-se dizer que esse movimento popularizou a capoeira no Brasil e contribuiu significativamente para sua inclusão nas práticas da Educação Física escolar.

Já a Capoeira Contemporânea surgiu como uma proposta que visa a superação dos embates em torno da valorização da memória dos primeiros capoeiras ou da esportivização da capoeira9 . Gressoni (2013), em seu mestrado, faz um estudo empírico com mestres que se auto declararam praticantes de capoeira contemporânea visando compreender essa manifestação e conclui que a capoeira contemporânea:

[...] redimensionou ambas as escolas tradicionais como os pilares fundamentais da prática, rompendo assim com a separação angola/regional existente até então. Além disso, a capoeira contemporânea tende a dar liberdade para reestruturar-se a prática da capoeira criando novos fundamentos ou acoplando a eles características de outras práticas, como lutas ou acrobacias. (GRESSONI, 2013, p. IV).

Assim, o movimento da capoeira contemporânea ao adotar, em suas práticas, tanto característica da Capoeira Angola, como referência a cultura dos antepassados, como a ênfase nos movimentos acrobáticos mais visíveis na Capoeira Regional, amplia a compreensão da capoeira presentes nos movimentos tradicionais.

O samba e o carnaval são expressões da cultura afro-brasileira que têm grande significado nacional e internacional, são expressões da ludicidade humana, em que o brincar é essencial. Para Lopes (2005), o brincar num ritmo poderia ser a expressão que aproxima o samba brasileiro e, em particular, que dá origem ao carnaval como uma folia popular, uma festa que ultrapassa os atuais desfiles de Escolas de Samba.

As manifestações da cultura corporal afro-brasileira são difundidas nos meios de comunicação e vivenciadas em diversos espaços. No entanto, o que se observa é um processo de esportivização das expressões culturais, como exemplo disso há os festivais de danças, os concursos de escolas de samba e a tentativa de transformar a capoeira em um esporte olímpico. Aqui se entende por esportivização (BRACHT, 1992; 2005; GONSÁLEZ, 2014) a transformação e a regulamentação das manifestações culturais dentro da lógica competitiva, que busca a padronização dos movimentos, a especialização, o recorde e a consagração do vencedor.

8. As graduações na capoeira são representadas por cordas ou cordéis, construídas em algodão, que o praticante usa preso à cintura e também serve com um cinto da calça do seu uniforme. As cores variam de escola para escola, sendo comum adotar variação de cores conforme o símbolo ou bandeiras de cada escola ou grupo de capoeira.

9. "O processo de esportivização da capoeira no cenário contemporâneo vem se dando pela consolidação de sua faceta esportiva, não só pela compreensão da legitimidade da capoeira como esporte, mas também, por conta do aumento do número de competições organizadas, seja ela federada ou não. A faceta esportiva da capoeira é ainda um campo de conflito de ideias a respeito de sua legitimidade como esporte, havendo uma convergência de pensamentos conservadores que desclassificam tal perspectiva esportiva, e de otimistas que pensam na esportivização como um processo de ressignificação, inerente à capoeira e ao contexto na qual se insere contemporaneamente" (MAROUN; SOUZA; MOURÃO, 2015, p. 17). 
Assim, a dança afro-brasileira, a capoeira e o carnaval com origem na cultura popular são expressões corporais repletas de alegria e de brincadeira e que, talvez por isso, têm dificuldades de serem trabalhadas na escola. A escola historicamente é local da cultura erudita, dos conhecimentos científicos e das belas artes, os quais são considerados como "superiores" ao senso comum ou aos saberes populares. O próprio fato de a cultura afro-brasileira estar vinculada aos povos oprimidos pode ser motivo de rejeição, visto que, em conformidade com Freire (1987), valoriza-se sempre os saberes do opressor enquanto possuidor de um patrimônio cultural dominante. Essas são análises a priori referentes ao ensino da cultura afro-brasileira na escola, porém existem ações pedagógicas que conseguem ressignificar os tempos e espaços escolares, construindo práticas que envolvam aspectos significativos da cultura afro-brasileira.

\section{Apresentação e análise dos dados}

Ao identificar 170 trabalhos publicados entre o período de 1989 e 2017, observou-se que o número de publicações tem crescido significativamente no decorrer do tempo, como se pode observwar na tabela que segue:

\begin{tabular}{|c|c|}
\hline Ano & N. ${ }^{\circ}$ \\
\hline 1989 & 1 \\
\hline 1991 & 5 \\
\hline 1993 & 5 \\
\hline 1995 & 4 \\
\hline 1996 & 2 \\
\hline 1997 & 1 \\
\hline 1999 & 4 \\
\hline 2000 & 2 \\
\hline 2001 & 6 \\
\hline 2002 & 1 \\
\hline 2003 & 5 \\
\hline 2005 & 12 \\
\hline 2006 & 1 \\
\hline 2007 & 10 \\
\hline 2008 & 4 \\
\hline 2009 & 10 \\
\hline 2010 & 11 \\
\hline 2011 & 20 \\
\hline 2012 & 9 \\
\hline 2013 & 10 \\
\hline 2014 & 7 \\
\hline 2015 & 8 \\
\hline 2016 & 8 \\
\hline 2017 & 24 \\
\hline Total de Publicações & 170 \\
\hline
\end{tabular}

Nos dados da Tabela 1, fez-se a seguinte análise: com a abertura democrática em 1985, o crescimento das reflexões críticas na Educação Física e o surgimento da proposta pedagógica que apontam a capoeira 
com conteúdo escolar (SOARES et al., 1992) impulsionaram a produção teórica referente à inserção da cultura afro-brasileira na escola. Os primeiros trabalhos relevantes encontrados foram: Depoimento do ideário Beribazu de capoeira, realizado pelo Mestre Zulu (1989) no VI Congresso Brasileiro de Ciências do Esporte (CONBRACE). O texto apresenta os princípios da capoeira trabalhados e defendidos pelo Mestre Zulu e relata a iniciativa de introduzir a capoeira na rede pública do Distrito Federal e nos Jogos Escolares Brasileiros. Observou-se que a inclusão da capoeira na Educação Física no Distrito Federal foi um marco na tentativa de tematizar a cultura corporal afro-brasileira na escola. Essa experiência foi objeto de estudo que gerou outras publicações, tendo como exemplo o trabalho de Falcão (1994). Esse autor faz uma análise da experiência com o ensino de capoeira no Distrito Federal e conclui que essa iniciativa teve uma relevante contribuição para a inclusão e reflexão da capoeira com conteúdo da Educação Física escolar.

Também, na Tabela 1, verifica-se que, a partir de 2005, o número de produções referentes à temática tem, em média, 10 publicações por ano. Pode-se constatar que o aumento dos trabalhos publicados é subsequente à Lei $\mathrm{n}^{\circ} 10.639$ (BRASIL, 2003), que incluiu, no currículo oficial da rede de ensino, a obrigatoriedade da temática "História e Cultura Afro-Brasileira". Esse fato, por si só, tem gerado investigações como esta pesquisa, que buscam compreender como a Educação Física vem implementando a obrigatoriedade dos estudos da cultura afro-brasileira na escola.

Na sequência, analisaram-se os trabalhos que se referem à capoeira enquanto prática corporal afro-brasileira; à dança e cultura afro-brasileira; e ao negro e quilombolas como objetos de estudo na Educação Física.

Tabela 2 - Agrupamento dos trabalhos por características das publicações

\begin{tabular}{lcccc}
\hline Trabalhos Publicados & Capoeira & Dança & Negro - Quilombolas & Subtotal \\
\hline Pesquisa & 78 & 11 & 19 & 108 \\
Pesquisa e Experiência de Ensino & 10 & 1 & 3 & 14 \\
Ensaios - Propostas & 8 & 3 & 2 & 13 \\
Resenhas & 2 & 0 & 1 & 3 \\
Experiências - Ensino & 25 & 3 & 4 & 32 \\
Total & $\mathbf{1 2 3}$ & $\mathbf{1 8}$ & $\mathbf{2 9}$ & $\mathbf{1 7 0}$ \\
\hline
\end{tabular}

Fonte: Elaborada pelo autor.

Observa-se que a maioria dos trabalhos publicados refere-se a resultados de pesquisas tem como objeto de estudo a capoeira, a dança, o negro e os quilombolas. Em segundo lugar, aparecem os relatos de experiências, seguidos por propostas de trabalho, pesquisas sobre experiência de ensino e resenhas.

Os trabalhos de pesquisa abordam diversos temas relacionados à capoeira, à dança, aos negros e aos quilombolas. As pesquisas relacionadas à capoeira enfocam os seguintes temas: princípios educacionais da capoeira (22 trabalhos), produção de conhecimento sobre capoeira (12 trabalhos), história da capoeira (10 trabalhos), esportivização e instrumentalização da capoeira (10 trabalhos), corpo do "capoeira" (6 trabalhos), destrezas dos "capoeiras" (5 trabalhos), capoeira e profissionalização (3 trabalhos), Capoeira Angola (4 trabalhos), capoeira símbolo de resistência de um povo (4 trabalhos), capoeira e gênero (2 trabalhos). As pesquisas relacionadas à dança abordam conceito e conhecimentos em dança afro, princípios educativos da dança, performance e cultura popular. As pesquisas relacionadas à cultura corporal, negro e quilombolas abordam temáticas como: aspectos históricos, cultura quilombola e corpo negro.

Além das pesquisas, constatou-se um número significativo de ensaios nos quais se propõem formas distintas de trabalhar a capoeira e a dança. Também se encontraram 3 resenhas que tratam de livros relacionados à capoeira e ao negro no esporte.

Entre os 170 trabalhos encontrados, priorizou-se a análise de 32 relatos de experiência e 14 pesquisas referentes a experiências de ensino, identificando as seguintes categorias: como é trabalhada a cultura afro-brasileira na escola; atividades da cultura corporal afro-brasileira abordadas na escola; procedimentos metodológicos adotados; fundamentação teórica que sustenta o trabalho com a cultura corporal afro-brasileira.

Para melhor identificar essas categorias, analisou-se em separado os trabalhos relacionados à capoeira, dança e cultura afro-brasileira, negra e quilombola. 


\section{A capoeira enquanto prática corporal afro-brasileira}

Referente à capoeira, identificaram-se 35 publicações que relatam experiência de práticas pedagógicas. As categorias específicas adotadas para compreender como a capoeira é trabalhada na escola foram: os espaços institucionais em que a capoeira está incluída; os profissionais que trabalham com capoeira; as estratégias pedagógicas adotadas para o trabalho com a capoeira e os referenciais teóricos mais citados nos trabalhos.

Após a leitura dos trabalhos, constatou-se que a capoeira enquanto cultura corporal afro-brasileira ocupa os seguintes espaços institucionais: atividades extraclasse promovidas pela própria escola (10 trabalhos); atividades extraclasse promovidas por programas universitários, tanto de extensão como de Programa Institucional de Bolsas de Iniciação à Docência (PIBID) (13 trabalhos) e incluída como conteúdo das aulas regulares de Educação Física (12 trabalhos).

Como se observa, têm crescido significativamente as experiências de trabalho com a capoeira, fruto de uma longa luta como de Zulu (1989), Soares et al. (1992), Falcão (1994, 1998, 2004), entre outros. Contudo, os dados analisados levam a constatar que a luta pela inclusão da capoeira no currículo escolar ainda continua, visto que os trabalhos relatam experiências realizadas em atividades extraclasses e por pessoas externas à escola. Essa constatação pode ser relativizada, porque é mais comum a participação em congressos, seminários e encaminhamento de artigos para a publicação por parte de profissionais com vínculo acadêmico. Essa é uma limitação da pesquisa bibliográfica porque se baseia em dados secundários, seria necessária a realização de um censo que levantasse dados sobre a percentagem de escolas que trabalham a cultura afro-brasileira nas aulas de Educação Física e isso demandaria a constituição de uma equipe ampla de pesquisadores.

No que concerne a quem ministra as aulas, observou-se que: 13 trabalhos foram escritos por professores de Educação Física efetivos das escolas; 9 por mestres de capoeira externos e 13 por bolsistas de extensão ou de PIBID. Constata-se que a preocupação com o ensino da cultura corporal afro-brasileira tem aumentado entre os estudantes de Educação Física, que buscam, em suas interversões escolares, abordar a proposta da inclusão da cultura afro-brasileira e indígena na escola. Porém, parece que ainda existe resistência em trabalhar com a cultura afro-brasileira como se pode observar pela pouca publicação de docentes efetivos que trabalham na escola. Essa resistência foi constatada em estudos anteriores (CORRÊA, 2012), onde se identificou que os estudantes não querem praticar capoeira, alegando que não é atrativa e é uma atividade muito cansativa.

Parece que a resistência se expressa também pelos poucos relatos de experiências relacionados ao ensino de capoeira, predominando pesquisa com temáticas variadas (corpo, aptidão física, características das rodas de capoeira, etc.) e ensaios propondo metodologias de ensino. Como a maioria das experiências observadas é realizada por profissionais externos, parece que a inserção da capoeira na escola é influenciada por outras instituições (universidades e escolas de capoeira) e não pela compreensão e aceitação dessa prática cultural pelo corpo docente efetivo das escolas, como identificado pelo número significativo de projetos extraclasse e por pessoas externas à escola e/ou vinculadas a outras instituições.

Quanto aos procedimentos metodológicos adotados para o trabalho com a capoeira, foram descritos superficialmente, sobretudo nos resumos que não descrevem detalhadamente os passos para o ensino da capoeira. No entanto, foi possível observar a predominância de aspectos metodológicos próprios da capoeira, muito detalhado por Zulu (1989), como é o caso de procedimentos como: roda, oficina de movimentos e apresentações culturais. Também se identificou a preocupação em trabalhar com os elementos da musicalidade e gestualidade da capoeira. Nas produções analisadas, encontraram-se as seguintes estratégias metodológicas: roda, 12 trabalhos; musicalidade e gestualidade, 12 trabalhos; apresentações culturais, 4 trabalhos; oficinas, 10 trabalhos; historicidade, 9 trabalhos; e ensino de fundamentos, 5 trabalhos. Observou-se também que a capoeira angola aparece com um procedimento metodológico em 7 trabalhos.

Importante destacar que a roda definida como um elemento característico da capoeira é utilizada tanto para jogar como para dialogar, é o momento de troca de conhecimentos práticos e teóricos. Segundo Abib (2004, p. 131), “[...] é justamente na tradição oral, presente na roda de capoeira, que os saberes têm o espaço e o tempo de se mostrarem e ser transmitidos pelos iniciados aos mais novos". 
Outro procedimento é o ensino simultâneo da musicalidade e da gestualidade, esse aspecto da capoeira possibilita trabalhos interdisciplinares (Educação Física, História e Artes), o que foi observado em três estudos que relataram a aproximação com outros componentes curriculares presentes no currículo escolar.

O referencial teórico predominante nos trabalhos está vinculado às concepções pedagógicas críticas, sendo os autores mais citados: Coletivos de autores (Soares et al., 1992) citado em 19 trabalhos; José Luiz Cerqueira Falcão (FALCÃO, 1994; 1998; 2004), em 11 trabalhos; Paulo Freire (FREIRE, 1996), em 6 trabalhos. Além desses autores, outros vinculados às concepções críticas de Educação Física são citados. A presença da tendência crítica-superadora nas publicações com a cultura corporal afro-brasileira é compreensível, visto que a obra Metodologia do Ensino de Educação Física (SOARES et al., 1992) constitui-se num marco referencial crítico das últimas décadas para a Educação Física escolar e para a capoeira em particular, com a introdução desta como conhecimento da cultura corporal afro-brasileira a ser trabalhado na escola.

Os seguintes autores também foram citados, pelo menos, em 4 trabalhos: Rego (1968), Reis (2000) e Areias (1984). Como nas últimas décadas tem sido ampliada a produção teórica referente à capoeira na escola, encontram-se diversas publicações referentes à temática, porém a maioria referenciada em Soares et al. (1992) e Falcão (1994; 1998; 2004).

Em síntese, apesar de se encontrarem outras experiências de trabalho com a cultura corporal afro-brasileira na escola, a capoeira é apresentada como a atividade mais citada para a inclusão da manifestação cultural de matriz africana na escola.

\section{Dança e cultura afro-brasileira}

Ao observar as publicações que tratavam da dança afro-brasileira, encontraram-se poucos trabalhos que abordam o ensino da dança na escola, a maioria refere-se à dança como expressão cultural e artística. Dos 11 resumos e artigos que enfocam a dança, 1 trata das características do congo ${ }^{10}, 1$ aborda o maracatu $^{11}, 2$ relatam a história de blocos carnavalescos de Salvador e 7 identificam manifestações da dança na escola e em comunidades quilombolas. Os estudos analisados destacam a perda da identidade cultural das comunidades quilombolas e o pouco trabalho com a dança de matriz africana na escola. Em estudos anteriores (CORRÊA; MORO, 2004) já se apontavam as raras experiências da inclusão da dança na escola. Dos 4 relatos de experiências identificados, observou-se que a dança de matriz africana é trabalhada nas aulas de Educação Física (3 relatos de experiência) e nas aulas de Artes (1 relato). A dança de matriz africana é problematizada nas aulas de Educação Física em 2 trabalhos que propunham aos estudantes investigarem quais as danças são de origem africana. Um trabalho abordou, nas aulas de Educação Física, o congo, através de construção de instrumentos, vivências e apresentações. Outro enfocou o Samba de Véio ${ }^{12}$ (SV) que faz parte da tradição cultural da região do Sertão do São Francisco (BA) e foi trabalhado nas aulas de Educação Física e de Artes.

Referente à dança, conclui-se que é uma manifestação cultura pouco trabalhada no currículo escolar da Educação Física e de Artes e que necessita maior intervenção e experiências, como vem ocorrendo com a capoeira.

\footnotetext{
10. Anjos (2013 p. 19-20) observou, em seus estudos, que a dança congo "[...] é caracterizada por um bailado rigoroso, com algumas manobras complicadas sob ritmo cadenciante. É saltitante e marcada pela ginga e cruzamento de pernas e pés. Os movimentos são rápidos em direção horizontal, com deslocamentos laterais singulares ao movimento de um pêndulo. Os atores trocam de lugar e realizam evoluções".

11. Segundo Lima (2014, p. 307-308), “[...] o maracatu pode ser definido como uma manifestação cultural dotada de elementos diversos. Dispõe de dança, canto, fantasias e estilo musical próprio. Um maracatu é definido por sua música, cantada em geral por um mestre, que é acompanhado de batuqueiros, tocando afaias (os tambores), caixas, taróis, mineiros (espécie de ganzá) e gonguês (instrumento de ferro com uma campânula, percutida por um pedaço de madeira)".

12. O Samba de Véio é uma manifestação cultural da região de São Francisco-BA é uma dança em roda onde "Os homens formavam a banda de tocadores, enquanto as mulheres eram as sambadeiras, com vestidos coloridos e saias muito rodadas". (SÁ; SOUZA, 2010, p. 42).
} 


\section{Negro e quilombolas como objetos de estudo na Educação Física}

A respeito dos estudos sobre negro e quilombolas, nem todos são vinculados diretamente à Educação Física escolar, mas como um esforço para identificar ou caracterizar as atividades desses povos ou etnias. Identificaram-se 19 relatos de pesquisa, sendo que 9 tratam de descrever a cultura quilombola, 5 abordam o negro no futebol, 2 tematizam o corpo negro na Educação Física, um aborda os aspectos históricos da cultura corporal afro-brasileira e outro relato trata dos grupos de gongo. Além dos relatos de pesquisa, identificaram-se 2 ensaios, um sobre a proibição do batuque ${ }^{13}$ e outro sobre samba, futebol e malandragem como características da negritude. Encontrou-se uma resenha sobre o livro: O negro no foot-ball brasileiro de Mário Filho.

Dos 7 trabalhos que relatam experiências com o ensino da cultura corporal afro-brasileira, identificaram-se as seguintes iniciativas:

" 1 trabalho objetivou, na escola, as experiências dos estudantes com dança populares como o batuque e o marabaixo ${ }^{14}$;

» 1 trabalho identificou como é vivenciada a cultura afro-brasileira na escola;

» 1 que problematizou junto aos estudantes as manifestações da cultura afro-brasileira;

» 2 abordaram, nas aulas de educação física, a questão do racismo;

" 1 que trabalhou os jogos de origem africana;

» 1 trabalho abordou as manifestações da cultura afro-brasileira como maculelê e capoeira.

Quanto aos espaços institucionais para realizar esses trabalhos, tem-se que cinco deles foram nas aulas de Educação Física e dois como atividade extraclasse.

Os procedimentos metodológicos utilizados foram: pesquisas bibliográficas, debates e vivências de manifestações da cultura corporal afro-brasileira.

O referencial teórico predominante nessas experiências foi: Soares et al. (1992), Falcão (2004; 2006), Darido (2005), Daólio (1995). Esses autores buscam atribuir à Educação Física escolar a competência para trabalhar com a cultura corporal.

Constatou-se, nesta seção, que as experiências referentes à cultura corporal fazem parte da construção histórica de grupos culturais distintos e atribuem à escola a função de abordar essa temática com características regionais e étnicas distintas. No entanto, mesmo que as produções teóricas tenham avançado e, de certa forma, chegado a um consenso sobre a importância de a Educação Física incluir a cultura corporal afro-brasileira no currículo escolar, observou-se, nos relatos de experiências, a existência de trabalhos isolados e de perspectivas de autores críticos que buscam consolidar a cultura afro-brasileira na escola.

\section{Considerações finais}

No decorrer deste artigo, apresentou-se os resultados obtidos referentes aos seguintes temas: as formas de trabalhar a cultura afro-brasileira; as atividades da cultura corporal afro-brasileira trabalhadas nas aulas de Educação Física; as estratégias metodológicas adotadas; as concepções teóricas que fundamentam o trabalho com a cultura corporal afro-brasileira na escola.

Quanto às formas de trabalhar a cultura afro-brasileira, constatou-se que a capoeira é o principal instrumento de inclusão da cultura corporal afro-brasileira na escola, porém ainda está muito vinculada

\footnotetext{
13. Segundo Silva e Rosa (2017, p. 250), os batuques são "[...] manifestações de dança afro-brasileira que apresentam sua dramaturgia corporal construída no jogo e na relação com a ancestralidade".

14. Para Caldas, Maciel e Andrade (2018, p. 31), “[...] o marabaixo é uma dança de origem africana trazida pelos negros escravizados vindos da África para o Amapá, sendo atualmente a maior manifestação cultural do Estado. Uma das festividades do marabaixo é o seu ciclo anual, que se inicia após a Semana Santa, manifestado nas comunidades negras, com homenagens ao Divino Espírito Santo e à Santíssima Trindade, onde o culto religioso se mantém vivo, com os rituais religiosos que se iniciam no domingo de Páscoa, sempre com homenagens à Santíssima Trindade e ao Divino Espírito Santo".
} 
às atividades extraclasse. Parece que a cultura corporal afro-brasileira, mesmo que amparada por lei, entra na escola pela porta dos fundos ${ }^{15}$ e levada por militantes das pedagogias críticas da Educação Física.

Nas experiências relatadas, houve a predominância do ensino da capoeira, seguido de poucos exemplos de trabalho com dança de origem africana e afro-brasileira e algumas experiências que problematizam o racismo e o próprio significado da cultura afro-brasileira e africana.

Quanto às estratégias metodológicas, identificou-se a predominância da roda de conversa e da capoeira como perspectiva dialógica e crítica.

O referencial teórico predominante foi relacionado à concepção crítico-superadora, que orientou a maioria dos trabalhos analisados e com intervenções pedagógicas nas aulas de Educação Física.

Assim, pode-se dizer que este estudo problematizou o trabalho com a cultura afro-brasileira na escola e aponta essa temática como um objeto de luta curricular. Isso porque, mesmo amparado em lei, o ensino da cultura afro-brasileira nas aulas de Educação Física ainda predomina em ações isoladas e muitas delas em tempo e espaços distintos das disciplinas curriculares. Como se observou, as experiências pedagógicas, em sua maioria, ocorrem por intervenções externas à escola por projetos universitários ou por trabalhos de mestres de capoeira.

Como já se constatou em outro estudo (CORRÊA, 2012), a inclusão da cultura corporal afro-brasileira no currículo oficial encontra resistências, veladas ou não, tanto pelo corpo docente, como por parte das comunidades onde estão inseridas as escolas.

Mesmo tendo a intenção de ampliar a compreensão do trabalho com a cultura corporal na escola, esta pesquisa limitou-se à análise de dados secundários não abrangendo uma mostra significativa de unidades de ensino e aponta para a necessidade de realizar um censo escolar que identifique a abrangência do trabalho com a cultura corporal afro-brasileira na Educação Física escolar.

\section{Referências}

ABIB, Pedro Rodolpho Jungers. Capoeira angola: Cultura popular e o jogo dos saberes na roda. 2004. Tese (Doutorado em Ciências Sociais Aplicadas em Educação) - Universidade Estadual de Campinas, Campinas, 2004.

ANJOS, José Luiz dos. Festa, danças e representações: continuidade de tradições e plasticidades culturais. Movimento, Porto Alegre, v. 19, n. 3, p. 11-30, jul./set. 2013. Disponível em: https://seer.ufrgs.br/Movimento/article/viewFile/36533/26015. Acesso em: 15 jun. 2020.

AREIAS, Almir. O que é capoeira. 2. ed. São Paulo. Editora Brasiliense, 1984.

BRACHT, Valter. Educação Física e aprendizagem social. Porto Alegre: Magister, 1992.

BRACHT, Valter. Sociologia crítica do esporte: uma introdução. 3. ed. Ijúi: Ed. Unijuí, 2005.

BRACHT, Valter; GONZÁLEZ, Fernando Jaime. Educação Física Escolar. In: GONZÁLEZ, Fernando Jaime; FENSTERSEIFER, Paulo Evaldo. Dicionário Crítico de Educação Física. 3. ed. Ijuí: Editora Unijuí, 2014. p. 241-247

BRASIL. Lei no 9.394, de 20 de dezembro de 1996. Estabelece as diretrizes e bases da educação nacional. Diário Oficial da União: seção 1, Brasília, DF, p. 27833, 23 dez. 1996. Disponível em: http://www.planalto.gov.br/ccivil_03/Leis/L9394.htm. Acesso em: 24 jan. 2009.

BRASIL. Lei $\mathrm{n}^{\circ}$ 11.645, de 10 de março de 2008. Altera a Lei $\mathrm{n}^{\circ}$ 9.396, de 20 de dezembro de 1996, modificada pela Lei $\mathrm{n}^{\circ} 10.639$, de 9 de janeiro de 2003, que estabelece as diretrizes e bases da educação nacional, para incluir no currículo oficial da rede de ensino a obrigatoriedade da temática "História e Cultura Afro-Brasileira e Indígena". Diário Oficial da União: seção 1, Brasília, DF, p. 1, 11 mar. 2008. Disponível em: http://www.planalto.gov.br/ccivil_03/_ Ato2007-2010/2008/Lei/L11645.htm\#art1. Acesso em: 14 ago. 2009.

15. Usa-se essa expressão com a intenção de fazer uma analogia à discriminação do negro na sociedade brasileira, onde os trabalhadores prestadores de serviços costumam entrar nas residências pelas portas de serviços ou portas dos fundos. Conforme Martins (2012), os postos de trabalhos mais ocupados pela população negra ou parda no Brasil são serviços temporários, serviços domésticos, construção civil, entre outros trabalhos vulneráveis. 
BRASIL. Lei $\mathrm{n}^{\circ}$ 10.639, de 9 de Janeiro de 2003. Altera a Lei no 9396 de 20 de dezembro de 1996, que estabelece as diretrizes e bases da educação nacional, para incluir no currículo oficial da Rede de Ensino a obrigatoriedade da temática "História e Cultura Afro-Brasileira", e dá outras providências. Diário Oficial da União: seção 1, Brasília, DF, p. 1, 10 jan. 2003. Disponível em: http://www.planalto.gov.br/ccivil_03/leis/2003/110.639.htm. Acesso em: 24 jan. 2009.

BRASIL. Ministério da Educação. Base Nacional Comum Curricular: educação é a base. Brasília, DF: MEC, 2017. Disponível em: http://basenacionalcomum.mec.gov.br/images/BNCC_EI_EF_110518_versaofinal_site.pdf. Acesso em: 24 maio 2020.

CALDAS, Yurgel Pantoja; MACIEL, Kerllyo Barbosa; ANDRADE, Estrela Veg da Cruz de. Marabaixo: identidade e cultura de resistência. Identidade!, São Leopoldo, v. 23, n. 1, p. 26-43, jan./jul. 2018. Disponível em: http://periodicos. est.edu.br/index.php/identidade/article/view/3298/3050. Acesso em: 15 jun. 2020.

CAMPOS, Hellio. Capoeira regional: do abadá à beca. In: CAMPOS, Hellio. Capoeira regional: a escola de Mestre Bimba. Salvador: EDUFBA, 2009. p. 96-118. Disponível em: http://books.scielo.org/id/p65hq/pdf/campos-9788523217273-11.pdf. Acesso em: 15 jun. 2020.

CASTRO JÚNIOR, Luis Vitor. Capoeira angola: olhares e toques cruzados entre historicidade e ancestralidade. Revista Brasileira de Ciências do Esporte, Campinas, v. 25, n. 2, p. 143-158, jan. 2004.

CORRÊA, Ivan Livindo de Senna; MORO, Roque Luiz. Educação Física Escolar: reflexão e ação curricular. Ijuí: Editora Unijuí, 2004. 296 p.

CORRÊA, Ivan Livindo de Senna. Cultura corporal afro-brasileira na escola: resistência e perspectiva de estudantes do ensino médio. Cadernos do Aplicação, Porto Alegre, v. 25, n. 1, p. 81-105, jan./jun. 2012.

DAÓLIO, Jocimar. Da cultura do corpo. Campinas: Papirus, 1995.

DARIDO, Suraya Cristina; RANGEL, Irene Conceição Andrade. Educação Física na escola: implicações para prática pedagógica. São Paulo: Editora Guanabara Koogan, 2005.

FALCÃO, José Luiz Cerqueira. Capoeira. In: KUNZ, Elenor (org.). Didática da Educação 1. Ijuí: Editora Unijuí, 1998. p. 55-94.

FALCÃO, José Luiz Cerqueira. A escolarização da "vadiação": a capoeira na fundação educacional do Distrito Federal. 1994. Dissertação (Mestrado em Educação Física) - Escola de Educação Física e Desportos, Universidade Federal do Rio de Janeiro, Rio de Janeiro, 1994.

FALCÃO, José Luiz Cerqueira. O Jogo da capoeira em jogo e a construção da práxis capoeirana. 2004. Tese (Doutorado em Educação) - Faculdade de Educação, Universidade Federal da Bahia, Salvador, 2004.

FERREIRA, Marcelo Guina. Teoria da Educação Física: bases epistemológicas e propostas pedagógicas. In: FERREIRA NETO, Amarílio; GOELLNER, Silvana Viladre; BRACHT, Valter (org.). As ciências do esporte no Brasil. Campinas: Autores Associados, 1995. p. 193-224.

FRANCO, Maria Laura P. B. Análise de conteúdo. Brasília, DF: Liber Livro Editora, 2008.

FREIRE, Paulo. Pedagogia da Autonomia. Rio e Janeiro: Paz e Terra, 1996.

FREIRE, Paulo. Pedagogia do Oprimido. 17. ed. Rio e Janeiro: Paz e Terra, 1987.

GONZÁLEZ, Fernando Jaime. Esportivização. In: GONZÁLEZ, Fernando Jaime; FENSTERSEIFER, Paulo Evaldo. Dicionário Crítico de Educação Física. 3. ed. Ijuí: Editora Unijuí, 2014. p. 263-267.

GRESSONI, Franz Eric de Goes. Capoeira contemporânea: compreensões decorrentes de mestres autodeclarados. 2013. Dissertação (Mestrado em Ciências da Motricidade) - Instituto de Biociências de Rio Claro, Universidade Estadual Paulista, Rio Claro, 2013.

GUERRA, Denise. Um olhar sobre a cultura corporal de movimento afro-brasileira construída a partir da corporeidade africana. Revista África e Africanidades, [S. l.], ano 1, n. 2, ago. 2008. Disponível em: http://cev.org.br/arquivo/ biblioteca/4032603.pdf. Acesso em: 15 jun. 2020.

HALLAL, Pedro Curi; MELO, Victor Andrade de. Crescendo e enfraquecendo: um olhar sobre os rumos da Educação Física no Brasil. Revista Brasileira de Ciências do Esporte, Porto Alegre, v. 39, n. 3, p. 322-337, 2017. Disponível em: https://www.scielo.br/pdf/rbce/v39n3/0101-3289-rbce-39-03-0322.pdf. Acesso em: 15 jun. 2020.

LOPES, Nei. A presença africana na música popular brasileira. Revista Espaço Acadêmico, Maringá, n. 50, jul. 2005. Disponível em: https://meujazz.files.wordpress.com/2010/01/lopes-nei-a-presenca-africana-na-musica-popular-brasileira.pdf. Acesso em: 15 jun. 2020. 
LIMA, Ivaldo Marciano de França. Maracatu nação e grupos percussivos: diferenças, conceitos e histórias. História: questões \& debates, Curitiba, n. 61, p. 303-328, jul./dez. 2014. Disponível em: https://revistas.ufpr.br/historia/article/ viewFile/39020/23832. Acesso em: 15 jun. 2020.

MAROUN, Kalyla; SOUZA, Weslly Valério de; MOURÃO, Ludmila Nunes. O processo de esportivização da capoeira no cenário contemporâneo. Arquivos em Movimento, Rio de Janeiro, v. 11, n. 2, p. 7-18, jul./dez. 2015. Disponível em: https://revistas.ufrj.br/index.php/am/article/view/9255/pdf_62. Acesso em: 15 jun. 2020.

MARTINS, Tereza Cristina Santos. O negro no contexto das novas estratégias do capital: desemprego, precarização e informalidade. Serviço Social \& Sociedade, São Paulo, n. 111, p. 450-467, jul./set. 2012. Disponível em: https://www.scielo.br/pdf/sssoc/n111/a04.pdf. Acesso em: 15 jun. 2020.

MINAYO, Maria Cecilia de Souza. O desafio do conhecimento: pesquisa qualitativa em saúde. São Paulo: Hucitec; Rio de Janeiro: Abrasco, 1993.

MUGNAINI, Rogério; STREHL, Letícia. Recuperação e impacto da produção científica na era Google: uma análise comparativa entre o Google Acadêmico e a Web of Science. Encontros Bibli, Florianópolis, n. esp., p. 92-105, 2008. Disponível em: https://www.redalyc.org/pdf/147/14709808.pdf. Acesso em: 15 jun. 2020.

PAIXÃO, Maria de Lurdes Barros. Re-elaborações estéticas da dança negra brasileira na contemporaneidade: análise das diferenças e similitudes na concepção coreográfica do Balé Folclórico da Bahia e do Grupo Grial de Dança. 2009. 200 f.. Tese (Doutorado em Artes) - Instituto de Artes, Universidade Estadual de Campinas, Campinas, 2009.

REGO, Valdeloir. Capoeira Angola: ensaio sócio-etnográfico. Salvador: Editora Itapuã, 1968.

REIS, Letícia Vidor de Sousa. O mundo de pernas para o ar: a capoeira no Brasil. São Paulo: Publisher Brasil, 2000.

SÁ, Natália Coimbra de; SOUZA, Regina Celeste de Almeida. Culturas regionais no Rio São Francisco: perspectivas de análise do samba de véio. Revista de Desenvolvimento Econômico, Salvador, ano 12, ed. esp., p. 40-46, dez. 2010. Disponível em: https://revistas.unifacs.br/index.php/rde/article/view/1243/986. Acesso em: 15 jun. 2020.

SANTIN, Silvino. Educação Física: uma abordagem filosófica da corporeidade. 2. ed. Ijuí: Editora Unijuí, 2003.

SILVA, Renata de Lima; ROSA, Eloisa Marques. Performance negra e a dramaturgia do corpo no batuque. Revista Brasileira de Estudos da Presença, Porto Alegre, v. 7, n. 2, p. 249-273, maio/ago. 2017. Disponível em: https://seer.ufrgs.br/ presenca/article/view/63510. Acesso em: 15 jun. 2020.

SILVEIRA, Rozana Aparecida; CARDOSO, Fernando Luiz; SABBAG, Samantha. Relações de gênero e relação corporal entre praticantes de axé e hip hop. In: SEMINÁRIO INTERNACIONAL FAZENDO GÊNERO, 8., 2008. Anais [...]. Florianópolis: UFSC, 2008. Disponível em: http://www.fazendogenero.ufsc.br/8. Acesso em: 20 fev. 2011.

SOARES, Carmen Lúcia et al. Metodologia do Ensino de Educação Física. São Paulo: Cortez, 1992.

ZULU, Mestre. Depoimento sobre o ideário Beribazu de capoeira. Revista Brasileira de Ciências do Esporte, Campinas, v. 11, p. 64-68, set. 1989.

Data de submissão: 07/07/2020

Data de aceite: 08/09/2020 